\title{
Fetal diagnosis of congenital heart disease
}

\author{
Lindsey D. Allan
}

A LTHOUGHIUNDERSTANDTHECONCERNANDSTRENGTH of feeling behind the comments of Squarcia and his colleagues, ${ }^{1}$ there are other responses to the dilemma they identify. In the early years of my involvement in fetal cardiology, I was very unsure of my own stance. Since then, my viewpoint has been fashioned by the experience of direct involvement with a large group of patients. I have counselled over 1,000 mothers prenatally, of whom about half chose to interrupt the pregnancy. I have had the opportunity to follow the children of the continuing pregnancies, and the families of those parents who chose to interrupt. The suffering involved in the continuing pregnancies was many times greater than in the latter group. It involved not only the affected child, but also the siblings, the parents, the extended family and the medical personnel. In contrast, those parents who chose abortion never forgot their loss, but the pain was contained, they did recover from it, and ended up with a healthy family.

I would strongly challenge the contention that interruption of pregnancy is an "easy" course, as is suggested by Squarcia and colleagues. No mother reaches the midtrimester of pregnancy without wanting that child. In the three or four months since the pregnancy was diagnosed, the parents have already invested hopes and dreams in its future. To make the decision to abort the fetus is a tremendously courageous one, and one that is never made lightly. It is associated with some risk for the mother, but she and her partner make this decision as the child's advocate. They are not willing to accept the quality of life and limited life span that is offered the affected fetus, and are acting in order to prevent his or her suffering. Irrespective of the religious or moral beliefs of the parents, it is an extremely difficult course to choose. In fact, it is much easier not to intervene, and to submit to being a victim of fate.

As doctors and researchers, we must be scrupulously careful not to act out of self-interest in this setting. The truth and the whole truth, including what we do not know, is essential. Parents are indeed "alone and desper-

Accepted for publication 29 April 1996 ate" at this time. For the doctor to foster unfounded hopes for future miracles in this setring, therefore, is particularly morally reprehensible. We must continually question our motives. We must repearedly remind ourselves that we will not be living through repeated surgeries, our lives will not be restricted or our future curtailed, we will not see the sword of Damocles constantly hanging overhead. Thus, we have no right to insist that we "cannot give up." We must work with the parents to lead them to the decision which seems the best for them, and suppress our self-interest. We are not standing in the parents' shoes, nor will we ever be, so we have no right to judge them. We must be prepared to give the parents our unqualified support whatever they decide.

Society, quite rightly, is no longer willing to see the doctor as all powerful, or in a paternalistic role. Patients in all branches of medicine are not willing to let the doctor "try everything" and then let them live with the consequences. They want to make informed choices. They want the opportunity to exercise more control over major decisions affecting their health and future and that of their children. The challenge of the next century is for doctors to be able to provide the information that patients want, and to present it in a way that each patient can understand. This will not bring to a halt experimental therapeutic strategies on which our future depends, but will expose them plainly as such. Patients embarking on uncertain or untried courses will do so in an informed way and as a result of their own choice. The requirement of direct honesty from the doctor will hopefully temper research enthusiasm with humanity.

\section{Babies Hospital \\ Columbia University \\ New York, USA}

\section{Reference}

1. Squarcia U. Fetal diagnosis of congenital cardiac malformations: a challenge for physicians as well as parents. Cardiol Young 1996; 6: 256-257. 